\title{
SOLIDARIEDADE POLÍTICA E CONSTITUIÇÃO DE SUJEITOS: a atualidade dos movimentos sociais
}

\author{
Samira Kauchakje*
}

\begin{abstract}
Resumo: Este artigo apresenta parte dos resultados de pesquisa sobre movimentos sociais no Brasil e debate sobre a possível centralidade dos mesmos na atualidade. Para tanto, apresenta aspectos conceituais e da historicidade dos movimentos sociais e discute a relação entre eles e a participação social na atualidade. O objetivo é discutir esses movimentos como matriz que contribui para melhorar a qualidade cívica de outras formas de participação social, tais como: conselhos, fóruns e organizações não-governamentais (ONGs). Esta discussão encaminha a conclusão no sentido de compreender o significado dos movimentos sociais atuais para a constituição da sociedade, considerando, especialmente, a consolidação da solidariedade política e a constituição de sujeitos sociais.
\end{abstract}

Palavras-chave: movimentos sociais; participação social; solidariedade política; ator social; direitos.

\section{Introdução}

A afirmação de que os movimentos sociais não são fenômenos extravagantes ou excepcionais, mas são centrais e estão no cerne da vida social, foi difundida entre pesquisadores do fenômeno, em

\footnotetext{
* Docente no mestrado em Gestão Urbana e nos cursos de Sociologia e Serviço Social da Pontifícia Universidade Católica do Paraná (PUCPR). Coordenadora do Grupo de Pesquisa Gestão de Políticas Públicas e Movimentos Sociais nessa universidade. Doutora pela Universidade Estadual de Campinas (Unicamp, 1997). Tem publicações nos seguintes temas: políticas públicas, direitos, participação social e proteção social. E-mail: samira. kauchakje@pucpr.br
}

Artigo recebido em 23 maio 2007 e aprovado em 30 jun. 2008. 
particular, nos períodos próximos aos anos 1970 e 1980 (Castells, 1983, Touraine, 1989). Entretanto, em especial a partir de meados dos anos 80, uma questão recorrente é se essa afirmação tem enraizamento na atualidade ou se seria fruto da própria construção da modernidade e da consolidação de sua perspectiva ${ }^{1}$.

No Brasil, a questão é tratada em análises ${ }^{2}$ e no debate público sobre participação social em suas diversas configurações: sejam os experimentos e espaços (fóruns, orçamentos participativos, conselhos, por exemplo), sejam os instrumentos e mecanismos legais (conselhos, audiência pública, iniciativa popular, entre outros).

As análises e os debates são pontuados por reflexões de diferentes matizes sobre a reforma do Estado e a ideologia hegemônica da deslegitimação do Estado social, que, em uníssono, apregoam a responsabilidade sobre a questão social partilhada com a sociedade organizada (sobretudo as organizações não-governamentais) ${ }^{3}$. Além disso, tecem reflexões sobre o aparente recuo das teorias e projetos societários fundados numa visão de sistemas sociais, com explicações totalizadoras dos fenômenos sociais (em particular, teorias e projetos alinhados com as ideologias da família política da esquerda democrática e/ou socialista) ${ }^{4}$. Tal recuo tem relações imbricadas com a reestruturação produtiva combinada com o impacto das tecnologias da informação e comunicação nas esferas cultural, política e econômica ${ }^{5}$. Esses estudos lançam luz sobre os traços de uma nova fase do capitalismo que se espraia por territórios fluidos e não nacionais das organizações financeiras e da produção de riqueza em escala global, sem a construção de rebatimentos compensatórios e de regulamentação das relações econômico-políticas de abrangência planetária e em localidades ${ }^{6}$. Uma das expressões disso é a produção sem fronteiras da exclusão social - calcada na desigualdade sociocultural, particularmente na falta de empregos locais, dando lugar a fluxos migratórios e, em contrapartida, ao acirramento de 
políticas e sociabilidades assentadas em princípios xenófobos nos estados nacionais; outra expressão interligada são as incorporações e colisões internacionais com culturas não ocidentalizadas.

De toda forma, as análises trazem nuances que podem justificar a demarcação de uma nova era ou, mais modestamente, de uma nova configuração social mundial a partir de noções como "fim da sociedade salarial" (Castel, 1998); "emergência da sociedade em rede" (Castells, 1999a) e, em especial, a "crise ou modernidade radicalizada", bem como a "pós-modernidade" (Touraine, 1995; Santos, 2000; Harvey, 1992; Giddens, 2000).

Este artigo $^{7}$ pretende participar do debate e refletir sobre a correspondência ou não da afirmação da centralidade dos movimentos sociais, como categoria teórica e fenômenos empíricos, numa sociedade mundial e simultaneamente local - sociedade que guarda as características culturais, econômicas e políticas da modernidade e que, ao mesmo tempo, desnuda e torna cada vez mais nítidos elementos distintivos de novos arranjos geopolíticos, produtivos e de sociabilidade.

Para tanto, o artigo discute aspectos conceituais e da historicidade dos movimentos sociais com a finalidade de embasar e alinhar três pressupostos, que fazem parte de uma agenda de pesquisa em andamento ${ }^{8}$ : o primeiro é de que movimento social pode ser considerado matriz de outras formas e experimentos participativos; o segundo, de que práticas "movimentalistas" podem consolidar a solidariedade política, seja no âmbito das ações cívicas de afirmação de direitos e da proteção social, seja na esfera das inovações democráticas (com destaque para conselhos, organizações nãogovernamentais e fóruns); o terceiro, de que, diante dos pressupostos anteriores, se admite que a participação em movimentos sociais ou mesmo sua expressão na dinâmica social propicia a constituição de sujeitos sociais criativos na construção social. 
Para desdobrar esses argumentos, o artigo está divido em dois itens ${ }^{9}$ que tratam de: 1 ) aspectos conceituais e historicidade; 2 ) relação entre movimentos sociais e participação social na atualidade, cuja argumentação baliza a finalização do artigo.

\section{Aspectos conceituais e historicidade}

Movimento social é um fenômeno de diversas facetas, que acompanha a história das diferentes sociedades. Portanto, é mais apropriado tratar de movimentos sociais relacionando-os ao cenário social do qual emergem: revolta de escravos, seitas sociais e levantes camponeses da Antiguidade e da Idade Média; motins rurais do século XVIII; movimentos milenares do século XIX; movimentos socialista e trabalhista pós-Revolução Industrial; movimentos de bairro ou populares urbanos, os movimentos rurais brasileiros das últimas décadas e anteriores, bem como novos movimentos sociais, já na segunda metade do século XX.

Como objeto de análise, esse fenômeno está inserido num campo teórico que o descola, ao menos parcialmente, da realidade diversificada. Dessa forma, é possível ultrapassar as singularidades e particularidades de cada movimento social e abranger, em um mesmo conceito, fenômenos empíricos muito variados. O debate teórico sobre movimentos sociais teve grande incidência nos anos 1970 e 1980 e tratou, especialmente, dos movimentos de trabalhadores e populares urbanos, decrescendo a partir da década 1990, quando a temática mais comum abordava os denominados novos movimentos sociais, entre eles, os de gênero e ambientalista. Isso demonstra que a produção de conhecimento acompanhava a maior visibilidade de diferentes tipos de movimentos sociais e suas reivindicações. Mas a ocorrência de movimentos sociais e os estudos sobre eles são tanto anteriores a esses períodos quanto são atuais, porque movimentos sociais representam o conflito ou a contradição entre setores da 
população, pela conquista e/ou administração de recursos e bens econômicos e culturais e, também, por promoverem mudanças nas relações políticas instituídas de uma sociedade (ou, com menor freqüência, para mantê-las), e podem adquirir um caráter de luta de classes.

O movimento social clássico, para determinados enfoques teóricos, na sociedade industrial, por exemplo, é o movimento operário. Especialmente nas décadas de 1960 e 1970, alguns teóricos consideravam esse movimento como um campo de conhecimento à parte do movimento social em geral. É bastante provável que essa opção teórica estivesse refletindo tanto a repercussão e o impacto que o movimento operário teve nas diferentes sociedades, desde as primeiras aglomerações de trabalhadores nas fábricas das cidades, trazendo consigo mudanças sociais, econômicas, políticas e culturais, quanto a matriz teórica de raiz marxista, predominante, na época, na maioria das publicações sobre o tema, deixando opacos os movimentos sociais de tons classistas menos marcantes.

Conforme avança a segunda metade do século XX, o campo teórico dos movimentos sociais vai se alterando, sob a influência de novas e profundas modificações socioculturais e políticoeconômicas, bem como do debate acadêmico que não ignorou a “explosão de movimentos espontâneos que sacudiram a Europa no final dos anos 1960" (Doimo, 1993, p. 19). Os movimentos sociais e, de alguma forma, os próprios teóricos da área eram partícipes das mudanças de valores e das imagens que marcaram a época: grupos sociais propondo alternativas de comportamentos sexuais e políticos e de relação tanto com a natureza quanto entre culturas.

Nas últimas décadas do século XX, as investigações e análises sobre movimento social modificaram-se no bojo das crises das utopias e das teorias que as sustentavam até então. Nesse contexto, ressalta-se o desmantelamento dos regimes socialistas existentes 
no leste europeu e a crise no campo teórico-marxista, em termos da legitimidade metodológica, e como campo frutífero para análise social contemporânea, que "acabaram por marcar a configuração de um novo tempo: o tempo dos novos movimentos sociais” (idem, ibidem). Esse fator está conjugado à "crise das teorias racionalistas e humanistas abraçadas tanto pelo capitalismo liberal quanto pelo comunismo" e, também, ao tensionamento da hegemonia propositiva de políticas socioeconômicas dos Estados-nação, que vão sendo, progressivamente, solapadas por "uma economia mundial única, cada vez mais integrada e universal, operando em grande medida por sobre as fronteiras do Estado” (Hobsbawm, 1995, p. 19, 24). Os chamados novos movimentos, que enfatizam mais as diferenças étnicas, culturais, de gênero ou questões geracionais e ambientalistas, por exemplo, do que as desigualdades de classe, parecem ter a perspectiva das transformações culturais e políticas substantivas a partir da cotidianidade dos atores envolvidos (Scherer-Warren, 1993, p. 17).

Nos primeiros anos do século XXI, no campo teórico sobre movimentos sociais, ganha destaque o tema das redes sociais ${ }^{10}$ nas quais os movimentos sociais são um dos atores, embora, como se argumenta neste artigo, um ator relevante para a constituição de sujeitos políticos. Isto é, as redes sociais não viriam substituir ou diminuir a importância dos movimentos sociais, porém, as que são articuladas em torno das lutas por direitos e da solidariedade política local e planetária são formadas por movimentos sociais em conjunto com outros atores, como: organizações não- governamentais, órgãos do sistema internacional de defesa de direitos e organizações do Estado.

A partir desse argumento é que se corrobora a afirmação de que o lugar analítico dos movimentos sociais nas sociedades, hoje, deve ser revisto para se compreender "a diversidade identitária dos sujeitos, a transversalidade nas demandas por direitos, as formas 
de ativismo e de empoderamento através de articulações em rede e, finalmente, a participação política das organizações em rede" (Scherer-Warren, 2006, p. 109).

São exemplos de tal perspectiva os estudos sobre as seguintes redes: a) DH Net - Rede de Direitos Humanos e Cultura -, que "funciona como portal de informações, oferece espaço gratuito em seu domínio para que diversas organizações não-governamentais [...] e integrantes do movimento de direitos humanos construam sua própria página na WWW” (Doimo, Mitre e Maia, 2005, p. 107); b) rede ambientalista que articula por meio da Internet, tal como a "coalizão dos grupos ambientais nos Estados Unidos, Canadá e Chile, formada a partir dos Friends of the Earth, Sierra Club, Greenpeace, Defender of Wildlife, The Canadian Environment Law Association e muitos outros...” (Castells, 1999b, p. 162); c) redes de identidade "articuladas em larga medida por ONGs feministas - ligando organizações de mulheres negras, mulheres indígenas, defensoras de direitos das lésbicas, feministas socialistas...” (Alvarez, 2000, p. 406); d) fórum social mundial que articula grupos de ONGs, movimentos e sindicatos para resistir e "propor alternativa à primazia do mercado e do capital internacional” (Gohn, 2003, p. 57); e) rede identificada em sítios da Internet conectados em torno do tema do direito à habitação em Curitiba - PR e que expressa uma forte interação entre organizações não-governamentais, fóruns e movimentos sociais (Kauchakje e Ultramari, 2007).

Todavia, a despeito das modificações no campo teórico e na configuração da realidade, as análises sobre movimento social quase sempre apresentam o traço comum de vinculá-lo ao processo de mudança social. Interessante observar essa concepção nas passagens de distintos autores em diferentes décadas: uma trata de redes e outra, de movimentos sociais.

Para Musso (2004), as imprecisões e ambigüidades na noção de rede que se encontra na literatura explicam tanto seu êxito e 
difusão nos meios acadêmicos quanto, também, seu descrédito como base conceitual. De toda forma, o autor entende que rede

[...] é a prótese técnica de utopia social. As verdadeiras revoluções são, hoje, as rupturas oferecidas pelas tecnologias de comunicação, a começar pela Internet, que realiza a utopia da associação universal pelas redes de comunicação. A rede leva sempre consigo um imaginário da transição entre a liberação de um sistema piramidal e hierárquico de que o Estado é o arquétipo e a promessa de um sistema futuro, o da associação universal, anunciador de um novo tipo de relação igualitária. (p. 34).

Doimo (1993) aborda, historicamente, a associação entre movimentos sociais e mudanças sociais e lembra que

[...] a idéia de movimento social, além de representar uma das fronteiras do pensamento utópico, adquiriu o mesmo perfil das palavras-mito, cuja natureza simbólica [...] é inversamente proporcional à sua rigorosa delimitação conceitual e empírica (p. 25).

Essa ausência de consenso está ligada ao fato de movimento social ser objeto de investigação que envolve interesses e paixões explícitos, pois a noção de movimento social "não descreve parte da realidade, mas é um elemento de um modo específico de construir a realidade social” (Renon, 1996, p. 500).

Esforços para a delimitação conceitual ocupam lugar privilegiado na teoria social da análise das manifestações coletivas, dos movimentos de massa, das revoltas e da multidão (Ianni, 1988). Existem correntes teóricas que entendem o movimento como expressão de uma disfunção no sistema social, até linhagens teóricas que o apreendem como cerne da história social ou, ainda, como condição de transformação social, seja com ênfase nas estruturas econômicas, seja com ênfase na esfera cultural.

Todavia, admitir que as teorias sobre movimentos sociais estão carregadas pelas matrizes teóricas e posições ideológicas e políticas 
nas quais os atores se movem é muito diferente de afirmar que não é plausível a construção da noção geral sobre o fenômeno, aos menos, no interior de cada linhagem, tradição ou campo teórico.

Uma possível noção geral pode ser elaborada nos seguintes termos: movimentos sociais são formas de ação coletiva ${ }^{11}$ com algum grau de organização e representam o conflito ou a contradição entre setores da população pela conquista e/ou administração de recursos e bens econômicos, culturais e políticos e, também, para promover modificações e transformações das relações instituídas de uma sociedade, havendo, igualmente, movimentos sociais que almejam a manutenção das instituições sociais. Movimentos sociais emergem das contradições fundamentais da sociedade e/ou de demandas conjunturais decorrentes de carências econômico-culturais. Esses fatores explicativos da emergência dos movimentos são mediados por elementos de práticas organizativas e participativas de grupos sociais; por suas interpretações e representações sociais sobre a experiência social e sobre as forças sociais que dizem representar, bem como sobre aquelas que antagonizam; pela posição de agentes externos e pelas políticas públicas existentes.

Nas sociedades herdeiras do pensamento e das movimentações sociais do período moderno-industrial, isto é, em que fazem sentido os "conflitos que se articulam em torno de dois elementos fundamentais: de classe e de exclusão de cidadania” (Melucci, 1997, p. 27), é possível estabelecer (não sem problemas de acomodação teórica e de relação com fenômenos empíricos) classificações ou tipos de movimentos sociais que ocorrem tanto no meio urbano quanto no rural, tanto local como globalmente, tais como: movimento dos trabalhadores, movimento popular, movimento de elites econômicas, movimento cultural, movimento ideológico, movimento estudantil, movimento messiânico e ligado à religião, movimentos sociais com demandas relativas às diferenças e especificidades, bem como às questões universais/planetárias (Gohn, 1997a; Kauchakje, 1997 e 2007a). 
No Brasil, como de resto em vários países industrializados ou em industrialização, nas primeiras décadas do século XX e anteriores a 1980, os movimentos de maior visibilidade foram os de trabalhadores urbanos e rurais e os populares, com ocorrências de movimentos messiânicos.

A partir dos anos 1980 - período correspondente ao aprofundamento da mundialização econômica com reestruturação produtiva e precarização dotrabalho, aos processos dedemocratização na América Latina e no leste europeu e ao ambiente cultural, local e global voltado para a organização da sociedade civil e fragilização de políticas estatais -, os movimentos sociais de maior visibilidade foram os relacionados à sustentabilidade social concentrada no eixo igualdade-diferença (diferenças e direitos específicos como de gênero, deficiência, ciclo de vida, por exemplo) e à sustentabilidade planetária (pacifismo, ambientalismo, biodiversidade, diversidade cultural, entre outros). Esses movimentos, chamados de novos, pareciam superar os movimentos de caráter classista e/ou religioso, em particular.

O final do século XX e o início do século XXI demonstraram que isso não é verdadeiro, nem mesmo para países europeus centrais de economia capitalista, como evidenciado por mobilizações de trabalhadores pela defesa de conquistas sedimentadas na legislação social ou por manifestações de feição xenófoba em defesa de postos de trabalho locais, em contraposição a etnias e minorias migrantes, e comprovado pelas lutas religiosas fundamentalistas, sejam elas regionais, sejam mais amplas, que contrapõem blocos de países capitalistas/liberais, com herança do racionalismo helênicoocidental e cristão, aos blocos de países representados como oriente, sobretudo de religião e política assentadas no islamismo.

Particularmente no Brasil, o movimento dos negros, o dos povos da floresta, o feminista, o ecológico, entre outros, foram 
conjugados aos de trabalhadores e populares, com destaque para o dos trabalhadores sem terra. Uma das razões para a existência, neste país, do agregado identitário dos movimentos ligados às diferenças e à universalidade de demandas com os movimentos mais tradicionais seria a perenidade do conflito referente à terra e ao trabalho no campo, associada à persistente desigualdade socioeconômica e à segregação urbana.

A inflexão nas expressões e visibilidade no campo "movimentalista" está presente, também, nos estudos teóricos ${ }^{12} \mathrm{e}$ corresponde (em contraposição ou em aceitação) à hegemonia, nos anos 1980 e 1990, do ideário e das propostas políticas neoliberais que produziram e fortaleceram a "crise" do Estado social e, dessa forma, fomentaram o deslocamento da solidariedade política perante a questão social para a solidariedade humanitária dos órgãos da sociedade civil empenhados nas ações sociais.

Nos dias de hoje, a conjuntura, ao mesmo tempo, valoriza o fortalecimento da sociedade civil (denominação que, agora, esmaece ou mescla as vertentes combativas por direitos, as associações e fundações do terceiro setor e de responsabilidade socioambiental empresarial) e reafirma a importância das políticas estatais.

Os próprios movimentos passaram a dar prioridade às articulações com organizações formais, tais como organizações nãogovernamentais e conselhos gestores de políticas, ou seja, o eixo da participação social pende para as parcerias ou para a relação com o setor público estatal.

\section{Movimentos sociais e participação social na atualidade}

Abordar a atualidade dos movimentos sociais é tarefa que exige: a) apreensão de suas demandas num período de longa duração e em espaços sociais específicos, assim como b) que sejam 
considerados em relação às outras formas de participação. As tendências e características dos movimentos sociais, hoje, em relação a esses fatores - duração, demandas, espaços sociais e articulações - podem ser apreendidas por aspectos e exemplos apresentados a seguir.

A reflexão sobre a duração dos movimentos sociais é auxiliada por dois exemplos de movimentos altamente relevantes no século XX: o dos trabalhadores e o feminista. Em tempos recentes, mesmo que haja menor freqüência ou possível virulência de manifestações como greves, passeatas e ocupações (embora, no Brasil, as ocupações e os assentamentos rurais sejam significativos), podem ser identificadas repercussões das conquistas trabalhistas nas resistências ao desmantelamento da legislação trabalhista, pela permanência das conquistas de regulações do trabalho formal e contra a desproteção social nos meios rural e urbano. Essas repercussões também são detectadas em seu contrário, ou seja, nos movimentos e grupos sociais que, diante de novas condições econômicas estruturais, visam a desmontar a arquitetura dos direitos conquistados.

Uma das expressões hodiernas dos movimentos dos trabalhadores são os experimentos urbanos ou rurais de cooperativas, autogestionários e de economia solidária; isto é, nesses arranjos produtivos alternativos, a perspectiva "economicista" é subordinada a um projeto societário e político quando sustentada pela presença ou pelo lastro dos movimentos sociais como o operário e o dos trabalhadores sem terra, conforme estudos organizados por Santos (2002). Nessa esteira, Lima (2004) chama a atenção para dois elementos presentes na organização das cooperativas:

[...] a externalidade de seus organizadores, ou seja, a presença do Estado, de sindicatos, ONGs e mesmo empresas; e sua heterogeneidade no espectro ideológico, que vai de grupos empresariais a movimentos socialistas. [...] As cooperativas 
atenderiam, dependendo de quem as organiza, desde rebaixamento de custos para empresas, passando pela formação de novos empreendedores capitalistas, até uma complexa democracia no trabalho. [...] Daí o diferencial [...] estaria na disposição dos membros em participarem desses empreendimentos e na sua adesão ideológica aos princípios autogestionários.

Outro exemplo para levar à reflexão sobre impactos e duração é o movimento feminista, que introduz mudanças de mentalidade e culturais no âmbito das políticas, das relações conjugais, afetivas, sexuais e do trabalho, como destacam Castells (1999b) e Hobsbawm (1995).

O movimento de mulheres, em geral, elucida também o aspecto das demandas, demonstrando que a mistura temática das demandas locais e globais é característica dos movimentos sociais atuais.

No fim dos anos 1980, [...] os movimentos de mulheres participaram sistematicamente da arena política global, particularmente da cúpula das Nações Unidas, quando lutaram para incorporar a abordagem de gênero de maneira generalizada e colocar os direitos das mulheres na agenda oficial dos Estados e dos órgãos internacionais. Nessa época nasceram as grandes redes de organizações feministas, como a Development Alternatives with Women for a New Era (Dawn) e a Women's Evironment Development Organization (Wedo) [...] (Charles e Ryckmans, 2003, p. 266).

Alvarez (2000) aponta que, a partir da década de 1990, houve um descentramento e uma quebra de fronteira temática no movimento feminista:

Muitas feministas passaram a afirmar que as lutas feministas não deveriam mais ficar confinadas a um conjunto de questões específicas ou de interesse principal ou exclusivo das mulheres [...]. As feministas deveriam reformular suas reivindicações históricas em resposta aos discursos contemporâneos nacionais e internacionais relativos aos direitos da cidadania [...] (p. 392). 
Apesar da mistura de plurais demandas, os principais temas dos movimentos sociais, hoje, podem ser agrupados em: identitários e culturais (gênero, etnia, ciclo de vida, diversidade cultural, por exemplo); direitos de cidadania, políticas e serviços públicos (mundo do trabalho, saúde, educação, segurança alimentar, direitos humanos, entre outros); transformações econômicas e políticas globais (projetos econômicos e sociais alternativos ao capitalismo, principalmente); sustentabilidade socioambiental local e global (meio ambiente, biodiversidade, pobreza, justiça social global, etc.).

A dinâmica social atual com o ambiente de rede, discutida anteriormente, promove o emaranhado dessas temáticas nos diversos movimentos sociais, bem como sua ocorrência simultânea em espaços locais e globais (Scherer-Warren, 2005). Portanto, para se apreender o aspecto espacial, é necessário acompanhar as articulações com outras formas de participação social em localidades e "mundializadas". É menos comum, hoje, encontrar movimentos sociais isolados temática ou espacialmente, sem articulação entre si, com outras formas de organização da sociedade civil nacional e internacional ou com órgãos públicos estatais.

Essa interconexão temática e espacial é ilustrada na pesquisa (Kauchakje, 2007b) sobre as articulações locais e internacionais dos movimentos e organizações sociais com sede em Curitiba (com atividades relativas aos direitos à habitação, à assistência social, à segurança alimentar, ao trabalho, à educação e à saúde). Foram identificados 318 atores sociais, dos quais o Quadro 1 destaca alguns que representam sua diversidade. 


\section{Quadro 1 - Atores sociais em Curitiba articulados em torno do direito à proteção social (nos temas da assistência social, educação, habitação, saúde, segurança alimentar e trabalho)}

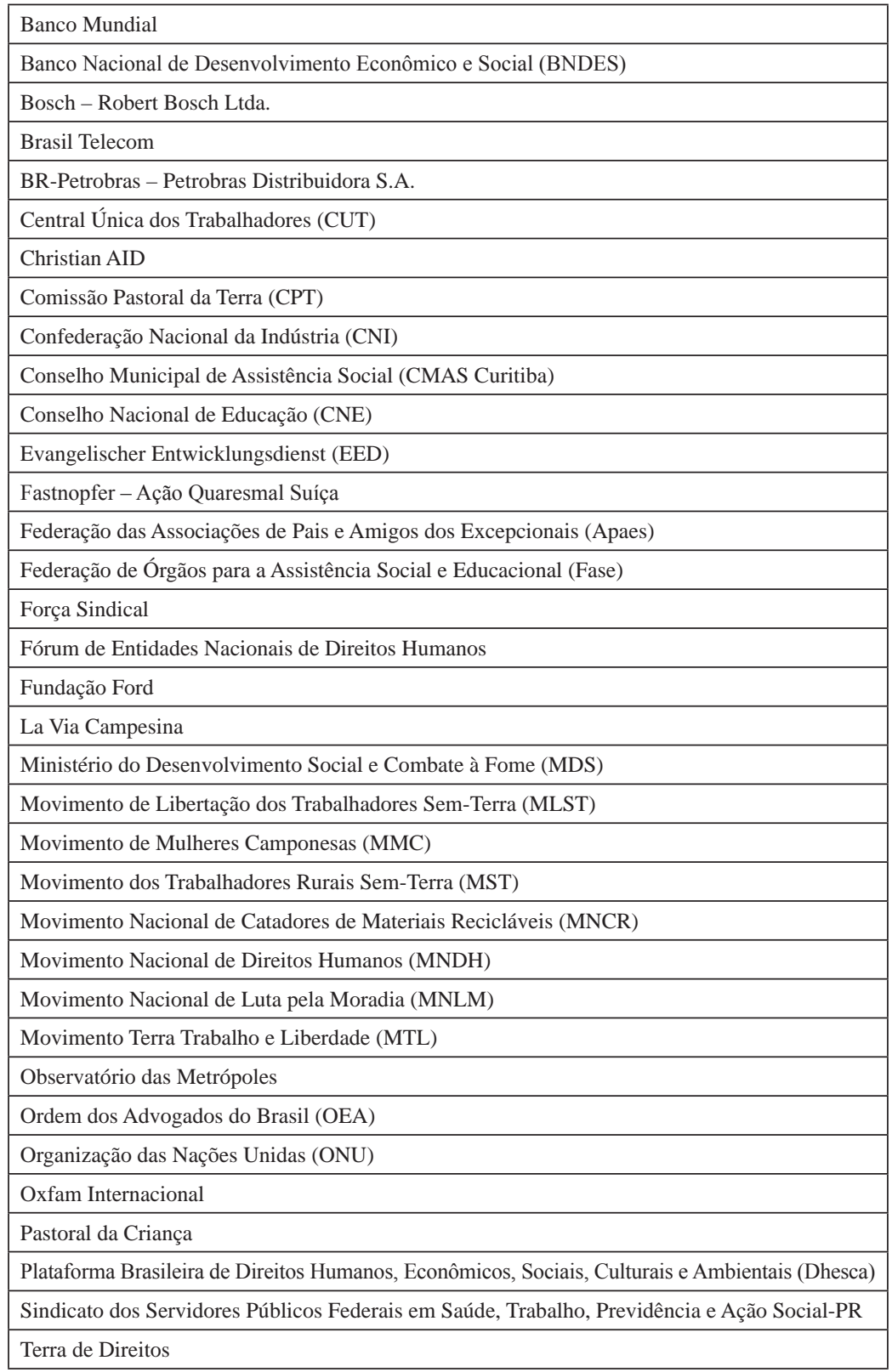


Os resultados da pesquisa demonstraram a extrapolação de fronteiras temáticas e espaciais de uma rede que articula movimentos sociais, órgãos de defesa de direitos, ONGs, empresas, Estado e entidades vinculadas a Igrejas ou confessionais. Assim, nessa rede, a alocação de recursos, projetos, propostas e discursos sobre a questão de direitos humanos e a proteção social se articulam e circulam transnacionalmente.

Essa circulação promove o risco de homogeneização ou de domínio de algumas organizações com maior poder de aglutinação de capital social e financeiro, bem como dos países nos quais elas estão sediadas, a respeito do entendimento sobre direitos e sobre quais segmentos populacionais seriam destinatários de ações de proteção social. Dito de outro modo, com os recursos, os projetos e os apoios das agências internacionais especialmente provenientes de países do capitalismo central, há o perigo unilateral de ingerência sobre as escalas locais por meio da difusão de valores e priorizações de públicos e objetivos de ações.

Com efeito, a nova agenda social global decorre, fundamentalmente, das experiências de umas poucas sociedades civis nacionais que dominam o mundo global das ONGs. Assim, o risco sério que corre o programa de uma democracia cosmopolita que tenha sustentação na sociedade civil global é o de buscar difundir, mundialmente, as experiências, as formas de percepção e os valores de uma meia dúzia de sociedades civis específicas (Costa, 2003, p. 10).

Esse risco precisa ser considerado nas análises dos movimentos sociais que hoje se articulam internacionalmente com diferentes organizações. Porém, como o próprio autor aponta, é possível considerar, também, que as localidades incorporam e ressignificam valores e recursos. Nesse caso, os recursos e discursos seriam incorporados e teriam resoluções nacionais e locais de acordo com sua gramática social e político-constitucional. Quer dizer, essa incorporação é mediada pela cultura e dinâmicas locais 
e pelos sistemas de direito, porque as sociedades dos chamados países periféricos - seus movimentos e organizações sociais - não são apenas reprodutoras, mas produtoras de concepções e de ações e transformam os discursos e práticas "recebidos" conforme suas dinâmicas relacionais, herança histórica e identidades culturais. Também essas sociedades são constituídas por sujeitos (no sentido de Touraine, 1995) que participam da construção da vida social, atribuem significado próprio à experiência individual e social e têm autonomia para interagir e direcionar mudanças de maneira criativa a partir de seu próprio contexto.

Portanto, a compreensão dos movimentos sociais, na atualidade, passa pela apreensão dos termos de suas articulações, em especial, com ONGs e conselhos gestores de políticas que são fundamentais na formação da agenda, nos processos decisórios e na implementação de políticas públicas.

A atenção para as relações entre movimentos sociais e $\mathrm{ONGs}^{13}$ justifica-se pelas razões que acabaram de ser expostas e, além disso, porque algumas organizações do terceiro setor (especialmente, as de caráter empresarial e filantrópico) imprimem em suas práticas uma baixa politização, isto é, tendem a transfigurar direitos em benesses sob responsabilidade do campo da solidariedade humanitária e/ou religiosa.

Uma das conseqüências disso é a subalternização de cidadãos reduzidos à figura de público-alvo ou beneficiário da ajuda e caridade social, quer dizer, a privatização da questão social. Vale lembrar que a privatização da questão social é um movimento regressivo e um retrocesso histórico, uma vez que o advento do próprio termo "questão social" significa o reconhecimento e a desnaturalização das situações de carências econômicas e culturais, bem como da exploração, entendida não mais como questão privada, natural ou de ordem divina, mas fundada nas contradições produzidas nas relações sociais concretas. 
Esse reconhecimento emergiu dos movimentos sociais do século XIX, nas sociedades capitalistas, herdeiras das revoluções gêmeas (industrial e política). As reivindicações foram na direção de que tais carecimentos não seriam mais objeto exclusivo de intervenções privadas no âmbito da solidariedade horizontal entre familiares e vizinhança ou conjugadas apenas com as ações de caridade da Igreja (sobretudo católica). Por sinal, os laços de pertencimento que sedimentavam a solidariedade horizontal já estavam sendo esgarçados ou rompidos com o advento da urbanização alavancada pela indústria e pelo modo de vida referente, assim como a importância da Igreja na condução da vida moral e política já havia sido enfraquecida na nova ordem social.

Movimentos ocorreram para que a questão social - e suas expressões, como habitação insalubre, saúde precária, falta de acesso à educação, expropriação do produto do trabalho, desemprego e incapacidade para o trabalho decorrente da idade e de invalidez - não fosse mais atendida por ações privadas nos vínculos de pertencimento ou por organizações humanitárias, mas fosse objeto de políticas e programas públicos, no âmbito prioritário do Estado e dos direitos, configurando a solidariedade política (Kauchakje, 2007a).

Sobre esse aspecto, a pesquisa mencionada sobre a rede de proteção social a partir de Curitiba constatou que há vínculos numerosos convergindo para os seguintes atores: Comitêde Entidades no Combate à Fome e Pela Vida (COEPPR); Alfabetização Solidária; Conselho Nacional de Secretários de Educação (Conced); Banco Mundial; Movimento Nacional de Direitos Humanos (MNDH); Fundação Itaú Social; Fundação Roberto Marinho; Ministério do Desenvolvimento Social e Combate à Fome (MDS); Ministério da Educação (MEC).

Neste caso, comparecem órgãos de estado, organizações do sistema financeiro, ONGs empresariais e de prestação de assessoria 
e serviços e movimento social no tema dos direitos humanos. A solidariedade humanitária e, em menor grau, a política parecem ser a liga dessas alianças.

Em outros espaços sociais, em particular, dos fóruns mundiais, os vínculos são criados por projetos societários, havendo, para além da mescla de temáticas reivindicatórias, uma mescla nas próprias características de ONGs produtoras de conhecimento, prestadoras de serviço e ativistas, conforme ressaltado por Scherer-Warren (2006). Tal misto de pluralidade e concentração de proposições parece ocorrer porque esse espaço está perpassado por movimentos sociais e organizações que convergem na diversidade das lutas por direitos e por alternativas solidárias e políticas.

Com as articulações movimentos-ONGs, os vínculos entre movimentos sociais e conselhos também contribuem para a compreensão sobre a atualidade dos movimentos sociais.

A depender do grau de autonomia e da politização dos representantes no conselho, estes podem servir mais à legitimação das decisões governamentais, no processo de gestão de políticas públicas, do que ao empoderamento da sociedade civil no controle e direcionamento do Estado (Fuks, 2005; Fuks e Perissinotto, 2006). Aparentemente, há um aumento de qualidade da participação social quando os conselheiros têm ou tiveram inserção em movimentos sociais ou se há o suporte e a pressão do campo "movimentalista" no que diz respeito aos processos decisórios dos quais participam. Fuks e Perissinotto (2006) afirmam que

[...] o legado constituído pelas lutas e alianças, a história prévia da área em questão, a forma pela qual o conselho foi instituído (por exemplo, como fruto de uma longa mobilização de forças sociais ou a partir da iniciativa do Estado), tudo isso define o "perfil" do conselho, condicionando, de alguma forma, a influência dos grupos nessa arena (p. 15). 
Esses autores investigaram o Conselho Municipal de Assistência Social de Curitiba (CMASC) no período de gestão 1999-2001 e puderam afirmar que, em seu processo de gestação e consolidação, o conselho contou

[...] com a atuação efetiva de várias forças ligadas aos movimentos populares e com instituições ligadas à esquerda. [...] A conduta do governo pautou-se por tentar se aliar aos representantes dos usuários, segmento composto majoritariamente por associações de bairro, e aos prestadores de serviço, formados por entidades filantrópicas, sempre com vistas a isolar o segmento dos trabalhadores do setor, inicialmente composto por entidades críticas ao governo (Central Única dos Trabalhadores e Conselho Regional de Serviço Social). [...] As seguidas derrotas e o controle ostensivo do setor governamental sobre o Conselho desestimularam as entidades de esquerda, levando-as a desistir de participar do conselho e consolidando, assim, o controle oficial sobre a instituição (idem, ibidem, p.16).

Na pesquisa sobre um conjunto de conselhos - CMASC, Conselho Municipal de Saúde de Curitiba (CMS), Conselho Municipal de Trabalho (CMERT) e Conselho Municipal dos Direitos da Criança e do Adolescente (Comtiba) -, esses autores concluíram que

[...] parece haver uma relação positiva entre, de um lado, ter vida associativa e, de outro, avaliar que a participação nos conselhos teve como efeito aumentar o interesse desses agentes por política. Assim, em princípio, a avaliação de que o interesse por política aumentou seria decorrência não apenas da experiência no Conselho, mas também da existência de algum vínculo associativo externo à instituição. [...] aqueles que pertencem a ONGs, movimentos religiosos e associações de bairro têm, majoritariamente, uma avaliação positiva acerca do crescimento do seu interesse por política depois de participar dos conselhos (idem, 2003, p. 6).

Portanto, no âmbito dos direitos de cidadania, uma estratégia seria o fortalecimento das articulações entre movimentos sociais 
com as outras formas de participação sociopolítica - por exemplo, fóruns, audiência pública, conferências e conselhos de políticas e ONGs - e destas entre si. Também é relevante que pesquisas acadêmicas elucidem o potencial democratizante dessas relações. Sobre isso, Costa (1997) adverte sobre a diferença de características e de inserção dos movimentos sociais nas esferas sociais e do Estado:

Os movimentos sociais apresentam perfis organizativos próprios, uma inserção específica na tessitura social e articulações particulares com o arcabouço político-institucional. [...] parece necessário reconhecer que as contribuições democratizantes desses movimentos não podem ser enxergadas unicamente a partir das instâncias institucionais, esperando-se deles o aperfeiçoamento dos mecanismos de intermediação de interesses ou a renovação da vida partidária [...]. Suas possibilidades residem precisamente em seu "enraizamento" em esferas sociais que são, do ponto de vista institucional, pré-políticas. E é no nível de tais órbitas e da articulação que os movimentos sociais estabelecem entre estas e as arenas institucionais que podem emergir os impulsos mais promissores para a construção da democracia (p. 10).

A centralidade dos movimentos sociais, na atualidade, parece decorrer do fato de eles serem uma matriz da democratização e da solidariedade política que contribui para a participação nos espaços de decisão e implementação de políticas públicas.

\section{Conclusão}

Como observado na literatura discutida, no campo investigativo, movimentos sociais não apenas descrevem parte da realidade, mas a pesquisa sobre eles já é um modo específico de interpretá-la. Tratar de movimentos sociais, portanto, tem um teor simultaneamente analítico e normativo, isto é, já atribui um sentido aos movimentos sociais. Portanto, a questão se os movimentos sociais 
são fenômenos centrais da vida social (também na atualidade) ou se essa interpretação seria fruto da própria construção e consolidação da modernidade e, assim, estaria perdendo importância nos dias de hoje pode ser reelaborada nos seguintes termos: qual o atual significado atribuído aos movimentos sociais para a constituição da sociedade?

Os argumentos e exemplos que o artigo mobilizou apontaram para a possibilidade de que a qualidade dos espaços e formas de participação sociopolítica esteja relacionada à sua articulação com movimentos sociais ou com a dinâmica social e pressão decorrente da existência desses movimentos na sociedade. Ao contrário, a ausência, deslegitimação ou opacidade de movimentos sociais pode trazer uma formalização e baixa qualidade da participação considerada como exigência formal/legal nas políticas e no Estado ou de cumprimento de regras para angariar financiamento para projetos sociais.

No Brasil, a recente ampliação do espaço público ocupado por ONGs, conselhos e outros canais de participação pode reproduzir relações políticas nas quais a noção de cidadania e de democratização das políticas e recursos públicos é pouco difundida. Entretanto, quando há vínculos com movimentos sociais de caráter de defesa de direitos, é possível que esse espaço público ampliado possa favorecer a constituição de sujeitos sociais com adesão às ações cívicas embasadas nos valores democráticos e no sentido da solidariedade política.

\section{Notas}

1 Uma leitura substancial que considera essa questão é Touraine (2006) e Scherer-Warren (2006).

2 Exemplos da produção teórica brasileira sobre os diversos formatos da participação da sociedade civil organizada: Avritzer e Navarro (2003), 
Benevides (1996), Dagnino, Alvarez e Escobar (2000), Gohn (2005), Kauchakje (2004/2005), Scherer-Warren (1993 e 2006) e Tatagiba (2002).

3 Para essa discussão, são importantes Arretche (2003), Draibe (1991), Nogueira (1999).

4 Para balizar esse debate sobre teorias sociais e ideários políticos, é interessante a leitura de Figueiredo (2001), Giddens (1989), Coutinho (2002).

5 Contribuem com o entendido sobre esse aspecto: Castells (1999a), Kauchakje, Penna, Frey e Duarte (2006), Graham (1996), SchererWarren (1999 e 2006), Dias e Silveira (2005).

6 Ver, por exemplo: Santos (2002), Duarte (1998), Hobsbawm (2001).

7 Uma versão com a discussão geral deste artigo foi apresentada no capítulo "Movimentos sociais no século XXI: matriz pedagógica para a participação sociopolítica” (Jezine e Almeida, 2007).

8 Trata-se da pesquisa sobre rede de direitos e proteção social na sociedade atual, cujo projeto em desenvolvimento "Rede sociotécnica de direitos nas cidades: proteção social mediada pela tecnologia em Curitiba” tem o fomento do Conselho Nacional de Desenvolvimento Científico e Tecnológico (CNPq) e da Fundação Araucária.

9 Parte dos itens tem por base a dissertação de mestrado e a tese de doutorado da autora (Kauchakje, 1992 e 1997).

10 As redes sociais, hoje, são compreendidas como "comunidades, virtual ou presencialmente constituídas” que operam em escala local, regional, nacional e internacional, com o objetivo de troca de informações, "articulação institucional e política e para a implementação de projetos comuns” (Rits, 2006). Dito de outro modo, as ONGs se articulam com movimentos sociais em "redes e fóruns locais, regionais, nacionais ou internacionais. As redes podem se articular em torno de pontos comuns, como, por exemplo, uma ação coletiva, temas ou identidades” (Abong, 2006). 
11 Ação coletiva refere-se a fenômenos coletivos que mobilizam um número significativo de pessoas em torno de objetivos pontuais ou históricos (nem sempre claramente explicitados) deliberados ou partilhados de forma comum. No geral, o objetivo é lograr o atendimento ou concretização de demandas políticas, econômicas e culturais não mensuráveis (solidariedade, identidade e direitos de cidadania, por exemplo) e vinculadas a valores e representações dos sujeitos sociais. As ações coletivas podem ser agrupadas em: lutas armadas e guerrilha; saques, depredações, quebra-quebras e motins; movimentos sociais e fóruns. Organizações não-governamentais ativistas (ou ligadas a lutas sociais), embora não possam ser consideradas ações coletivas, têm estreita relação tanto com essa noção quanto com suas práticas.

12 A tese de doutorado de Kauchakje (1997) demonstrou que houve diminuição do número relativo (comparado a outras temáticas) de dissertações e teses sobre movimentos sociais na Universidade de São Paulo (USP) e na Unicamp entre 1970 e 1995. Ao mesmo tempo, houve aumento da diversidade dos tipos de movimentos sociais abordados pelas pesquisas, passando da concentração sobre movimentos de trabalhadores e populares para um crescente interesse em novos movimentos sociais a partir da segunda metade dos anos 1980 .

13 As ONGs podem ser classificadas em produtoras de conhecimento, ativistas, de prestação de serviços (entre elas, as filantrópicas e as confessionais) e empresariais, segundo sugestões de Scherer-Warren (1999), Gohn (1997b) e Kauchakje (2004/2005).

Social actors and political solidarity: social movements today

Abstract: This article presents part of the results of our research about social movements as well as reflections on their importance in current societies. Its main goal is to understand the social movements' contribution in improving the civic quality of other forms of social participation, such as: councils, forums, and NGOs. The study focuses the concepts and history of social movements. The conclusion discusses the meaning of the present social movements for the constitution of the society, especially considering the 
consolidation of the political solidarity and the constitution of social actors.

Key words: social movements; social participation; political solidarity; social actor; rights.

\section{Referências}

ALVAREZ, Sonia E. A globalização dos feminismos latino-americanos. In: DAGNINO, Evelina; ; ESCOBAR, Arturo (Org.). Cultura e política nos movimentos latino-americanos: novas leituras. Belo Horizonte: UFMG, 2000.

ARRETCHE, Marta. Estado federativo e políticas sociais: determinantes da descentralização. Rio de Janeiro: Revan; São Paulo: Fapesp, 2003.

ASSOCIAÇÃO BRASILEIRA DE ORGANIZAÇÕES NÃOGOVERNAMENTAIS (Abong). Disponível em: <http://www. abong.org.br>. Acesso em: 3 out. 2006.

AVRITZER, Leonardo; NAVARRO, Zander (Org.). A inovação democrática. São Paulo: Cortez, 2003.

BENEVIDES, Maria Vitória. A cidadania ativa: referendo, plebiscito e iniciativa popular. São Paulo: Ática, 1996.

CASTEL, Robert. Metamorfoses da questão social: uma crônica do salário. Petrópolis: Vozes, 1998.

CASTELLS, Manuel. A sociedade em rede. São Paulo: Paz e Terra, 1999a.

. O poder da identidade. São Paulo: Paz e Terra, 1999b.

. The city and the grassroots. California: University of California Press, 1983.

CHARLES, Shofie; RYCKMANS, Hélène. O movimento de mulheres para uma outra mundialização. In: AMIN, Samin; HOUTART, François 
(Org.). Mundialização das resistências: o estado das lutas 2003. São Paulo: Cortez, 2003.

COSTA, Sérgio. Democracia cosmopolita: déficits conceituais e equívocos políticos.RevistaBrasileiradeCiênciasSociais, SãoPaulo,v.18,n.53, 2003. Disponível em: <http://www.scielo.br/scielo.php?script=sci_ arttext\&pid=S0102-69092003000300002\&lng=pt\&nrm=iso $>$. Acesso em: 24 ago. 2008.

- Movimentos sociais, democratização e a construção de esferas públicas locais. Revista Brasileira de Ciências Sociais, São Paulo, v. 12, n. 35, 1997. Disponível em: <http:// www.scielo.br/scielo.php?script=sci_arttext\&pid=S010269091997000300008\&lng=pt\&nrm=iso $>$. Acesso em: 24 ago. 2008.

COUTINHO, Carlos Nelson. Contra a corrente: ensaio sobre democracia e socialismo. São Paulo: Paz e Terra, 2002.

DAGNINO, Evelina; ALVAREZ, Sonia; ESCOBAR, Arturo. Cultura e política nos movimentos sociais latino-americanos: novas leituras. Belo Horizonte: UFMG, 2000.

DIAS, Leila Christina; SILVEIRA, Rogério Leandro Lima da (Org.). Redes, sociedades e territórios. Santa Cruz do Sul: Edunisc, 2005.

DOIMO, Ana Maria. Movimento popular no Brasil pós-1970: formação de um campo ético-político. 1993. Tese (Doutorado em Ciência Política) - Faculdade de Filosofia, Letras e Ciências Humanas (FFLCH), Universidade de São Paulo (USP), São Paulo.

; MITRE, Maya; MAIA, Rousiley. Movimentos sociais, internet e novos espaços públicos: o caso da DH Net. In: DIAS, Leila Christina; SILVEIRA, Rogério Leandro L. (Org.). Redes, sociedades e territórios. Santa Cruz do Sul: Edunisc, 2005.

DRAIBE, Sonia M. As Políticas sociais e o neoliberalismo: reflexões suscitadas pelas experiências latino-americanas. Revista da USP, 1991, v. 3, n. 17, p. 24-37. 
DUARTE, Fábio. Global e local no mundo contemporâneo. São Paulo: Moderna, 1998.

FIGUEIREDO, Vilma. "A ciência da sociedade" (25 Encontro Anual da Associação Nacional de Pós-Graduação e Pesquisa em Ciências Sociais - Anpocs, 2001). Disponível em: <http://www.anpocs.org. br/>. Acesso em: 5 jul. 2006.

FUKS, Mário. Participação e influência política no Conselho Municipal de Saúde de Curitiba. Revista Sociologia e Política, Curitiba, 2005, n. 25. Disponível em: <http://www.scielo.br/scielo.php?script=sci_ arttext\&pid=S0104-44782005000200006\&lng=pt\&nrm=iso $>$. Acesso em: 24 ago. 2008.

; PERISSINOTTO, Renato Monseff. Recursos, decisão e poder: conselhos gestores de políticas públicas de Curitiba. Revista Brasileira de Ciências Sociais, São Paulo, 2006, v. 21, n. 60. Disponível em: <http://www.scielo.br/scielo.php?script=sci_ arttext\&pid=S0102-69092006000100004\&lng=pt\&nrm=iso $>$. Acesso em: 24 ago. 2008. ; RIBEIRO, Ednaldo Aparecido. Cultura política e desigualdade: o caso dos conselhos municipais de Curitiba. Revista Sociologia e Política, Curitiba, 2003, n. 21. Disponível em: $<$ http://www.scielo.br/scielo.php?script=sci_arttext\&pid=S010444782003000200009\&lng=pt\&nrm=iso $>$. Acesso em: 24 ago. 2008.

GIDDENS, Antony. A constituição da sociedade. São Paulo: Martins Fontes, 1989.

- A terceira via: reflexões sobre o impasse político atual e o futuro da social democracia. Rio de Janeiro: São Paulo: Record, 2000.

GOHN, Maria da Glória. Fórum Social Mundial em Porto Alegre. In: (Org.). Movimentos sociais no início do século XXI. São Paulo: Cortez, 2003.

O protagonismo da sociedade civil: movimentos sociais, ONGs e redes solidárias. São Paulo: Cortez, 2005. 
. Os sem-terra, ONGs e cidadania. São Paulo: Cortez, 1997b.

Teorias sobre movimentos sociais. São Paulo: Loyola, 1997a.

GRAHAM, Stephen. Rumo à cidade em tempo real: desenvolvimento urbano numa sociedade globalizada e telemediática. Disponível em: <http://www.wisetel.com.br/espaco_de_futuros/vcidade.htm>. Acesso em: 8 dez. 2008.

HARVEY, David. A condição pós-moderna. São Paulo: Loyola, 1992.

HOBSBAWM, Eric. Entrevista sobre o novo século. São Paulo: Companhia das Letras, 2001.

. Era dos extremos: o breve século XX - 1914-1991. São Paulo: Companhia das Letras, 1995.

IANNI, Octavio. A sociologia e o mundo moderno. Revista PUC, São Paulo, n. 5, p. 18-32, nov. 1988.

JEZINE, Edineide; ALMEIDA, Maria de Lourdes Pinto de (Org.). Educação e movimentos sociais. Campinas: Alínea, 2007.

KAUCHAKJE, Samira. Alternatives pour recomposer les liens sociaux et la civilité dans les rapports sociétaires au Brésil. Revista Res Socialis, Fribourg Suisse, 2005, v. 24, p. 165-178.

. Gestão e controle de políticas públicas: participação social no Brasil contemporâneo. Revista Humanas, UFRGS, 2004/2005, v. 26/27, n. 1/2, p. 231-249.

. Gestão Social pública de serviços sociais. Curitiba: IBEPX, 2007a.

- Movimentos sociais na academia: um olhar sobre as teses e dissertações produzidas na Unicamp e USP entre 1970-1995. 1997. Tese (Doutorado em Educação) - Faculdade de Educação, Universidade Estadual de Campinas (Unicamp).

Movimentos sociais populares urbanos no Brasil de 1983 a 1990. 1992. Dissertação (Mestrado em Ciências Sociais Aplicadas) 
- Faculdade de Educação, Universidade Estadual de Campinas (Unicamp).

. "Rede sociotécnica de direitos: proteção social com suporte da tecnologia em Curitiba”. Relatório de pesquisa (Conselho Nacional de Desenvolvimento Científico e Tecnológico - CNPq), Curitiba, 2007b.

KAUCHAKJE, Samira; PENNA, Manoel Camillo; FREY, Klaus; DUARTE, Fábio. Redes socio-técnicas y participación ciudadana: propuestas conceptuales y analíticas para el uso de las TICs. Redes - Revista Hispana para el Análisis de Redes Sociales, dic. 2006, v. 11, n. 3, p. 1-26. Disponível em: <http://www.revista-redes.rediris. es>.

; ULTRAMARI, Clóvis. Rede sociotécnica do direito à habitação e a configuração do espaço em Curitiba. Cadernos Metrópole, PUCSP, 2007, v. 1, p. 63-76.

LIMA, Jacob Carlos. O trabalho autogestionário em cooperativas de produção: o paradigma revisitado. Revista Brasileira de Ciências Sociais, São Paulo, 2004, v. 19, n. 56. Disponível em: <http:// www.scielo.br/scielo.php?script=sci_arttext\&pid=S010269092004000300004\&lng=pt\&nrm=iso>. Acesso em: 24 ago. 2008.

MELUCCI, Alberto. Movimentos sociais e sociedade complexa. Cadernos do Núcleo de Estudos e Pesquisa sobre Movimentos Sociais, PUC, 1997, n. 2, p. 28-37.

MUSSO, P. A filosofia da rede. In: PARENTE, A. (Org.) Tramas da rede: novas dimensões filosóficas, estéticas e políticas da comunicação. Porto Alegre: Sulina, 2004.

NOGUEIRA, Marco Aurélio. Um Estado para a sociedade civil. In: RICO, Elizabeth Melo; RAICHELIS, Raquel (Org.). Gestão social: uma questão em debate. São Paulo: Educ: IEE, 1999.

REDE DE INFORMAÇÕES PARA O TERCEIRO SETOR (Rits). Disponível em: <http://www.rits.org.br/redes_teste/rd_oqredes. cfm>. Acesso em: 3 out. 2006. 
RENON, Karin D. Movimento social. In: BOTTOMORE, Tom; OUTHWAITE, William (Ed.). Dicionário do Pensamento Social do Século XX. Rio de Janeiro: Zahar, 1996.

SANTOS, Boaventura de Sousa (Org.). Produzir para viver: os caminhos da produção não capitalista. Rio de Janeiro: Civilização Brasileira, 2002.

SANTOS, Boaventura de Sousa. A crítica da razão indolente: contra o desperdício da experiência. São Paulo: Cortez, 2000.

SANTOS, Milton. A natureza do espaço: técnica e tempo; razão e emoção. São Paulo: Edusp, 2002.

SCHERER-WARREN, Ilse. Cidadania sem fronteiras: ações coletivas na era da globalização. São Paulo: Hucitec, 1999.

Das mobilizações às redes de movimentos sociais. Sociedade $e$ Estado, Dossiê Movimentos Sociais, Brasília, 2006, v. 21, n. 1, p. 109-130.

. Rede de movimentos sociais. São Paulo: Loyola, 1993.

. Redes sociales y de movimientos en la sociedad de la información. Nueva Sociedad, Venezuela, n. 196, mar./abr. 2005.

TATAGIBA, Luciana. Os conselhos gestores e a democratização fazem políticas públicas no Brasil. In: DAGNINO, E. (Org.). Sociedade civil e espaços públicos no Brasil. São Paulo: Paz e Terra, 2002, p. 47-103.

TOURAINE, Alain. Crítica da modernidade. Petrópolis: Vozes, 1995.

. Na fronteira dos movimentos sociais. Sociedade e Estado, Dossiê Movimentos Sociais, Brasília, 2006, v. 21, n. 1, p. 17-28.

. Palavra e sangue: política e sociedade na América Latina. Campinas: Unicamp, 1989. 